\title{
Repeating seismicity in the shallow crust modulated by transient stress perturbations
}

\author{
William B. Frank ${ }^{1}$, Nikolaï M. Shapiro ${ }^{2}$ \\ Institut de Physique du Globe de Paris, 75238 Paris, France \\ Allen L. Husker, Vladimir Kostoglodov \\ Instituto de Geofísica, Universidad Nacional Autónoma de México, 04150 Ciudad de México, Mexico \\ Michel Campillo ${ }^{3}$ \\ Institut des Sciences de la Terre, Université Grenoble Alpes, 38610 Gières, France
}

\begin{abstract}
Recent studies have reported seismic phenomena that are modulated by small stress perturbations $(<10 \mathrm{kPa})$, revealing their critically stressed nature. Such observations have been principally been limited to plate interfaces with their occurrence linked to high fluid pore-pressure. In this study, we report observations of nine repeating seismic sources in the shallow crust in Guerrero, Mexico that emit events at rates comparable to other seismic phenomena in low stress environments. Testing their susceptibility to small stress perturbations, we find that all nine sources appear to be modulated by mining activity, tides, and a large slow slip event (Mw 7.5). Our results suggest that the fault conditions necessary for low effective stress seismicity can occur away from plate interfaces.
\end{abstract}

Keywords: low effective stress, repeating seismicity, dynamic/static stress triggering, slow slip

\section{Introduction}

There has been a growing number of reports in the literature that have established links between the timing of seismic events and small stress perturbations, such as tidal oscillations and dynamic stresses from teleseismic earthquakes (e.g. Rubinstein et al., 2007; Peng et al., 2008; Thomas et al., 2009). Whether it be

5 along the deep roots of plate boundaries, as is the case for low-frequency earthquakes (Shelly et al., 2006) and tectonic tremor (Obara, 2002), or in the cryosphere (Peng et al., 2014), the triggering of such seismic events by stresses less than $10 \mathrm{kPa}$ imply that they occur under low effective normal stress. The critically stressed nature of both of these environments is most often explained by high pore fluid pressures, due to

\footnotetext{
${ }^{*}$ Corresponding author:

Email address: wfrank@mit.edu (William B. Frank)

${ }^{1}$ Now at Department of Earth, Atmospheric and Planetary Sciences, Massachusetts Institute of Technology, Cambridge, MA 02139, USA

${ }^{2}$ Also at Institute of Volcanology and Seismology FEB RAS, Petropavlovsk-Kamchatsky 683006, Russia

${ }^{3}$ Also at Department of Earth, Atmospheric and Planetary Sciences, Massachusetts Institute of Technology, Cambridge, MA 02139, USA
}

(C) 2016. This manuscript version is made available under the Elsevier user license http://www.elsevier.com/open-access/userlicense/1.0/ 
metamorphic dehydration at plate interfaces (Thomas et al., 2009; (Audet et al., 2009; Song et al., 2009) and

10 the presence of water throughout the cryosphere.

Given the low effective stress environment of these seismic events, the rupture cycles and consequently the event rates of these seismic events are much quicker than classical earthquakes. Though low effective stress events occur at rapid rates, the term repeating earthquakes is most often used to refer to moderately sized earthquakes located in the shallower portions of plate interfaces that repeat every few months or years (e.g.

15 Vidale et al., 1994; Nadeau et al., 1995). Based on their spatial distribution and inter-event times, several studies have used the timing of repeating earthquakes to estimate the slow deformation in creeping patches along plate interfaces (Nadeau and McEvilly, 1999; Igarashi et al., 2003; Uchida et al., 2003).

We focus on a dense linear seismic network (Caltech, 2007) in Guerrero, Mexico that operated during the large 2006 slow-slip event that occurred at $45 \mathrm{~km}$ depth and produced a dislocation of about $16 \mathrm{~cm}$ along

20 the subduction interface with an equivalent magnitude of Mw 7.5 (Kostoglodov et al., 2010; Radiguet et al., 2011) (see Fig. 1). A recent effort to systematically search within this continuous dataset for repeating seismicity generated a dense catalog of more than 1.8 million low-frequency earthquakes (Frank et al., 2014). The detection method consists of two steps, the first of which is an automatic detection algorithm proposed by Frank and Shapiro (2014), called the beamformed network response, that consists of searching through

25 a dataset for seismic energy that originates from a theoretical source location. Then each of the detected events are used as an event template in a matched-filter search (Gibbons and Ringdal, 2006), a network-based search that correlates template waveforms in a sliding window across all stations and components to look for events whose waveforms are significantly similar to those of the template. With a large enough seismic network, this powerful detection tool that can even identify events hidden within the ambient noise.

30 The family of multiplets, defined as the events detected using a given template and representing the seismicity originating from a single source, are more easily characterized than the templates themselves thanks to increased signal-to-noise ratios after the constructive stacking of the multiplet waveforms. The event family at any given source represents a time history of the stress and slip regimes at that location and has been used to reveal small transient slip events (Frank et al., 2015a). Not all of the event families detected in Guerrero, Mexico by Frank et al. (2014), however, were identified as low-frequency earthquakes located along the plate interface. We study here a group of nine event families comprised of 8121 events that represent superficial rapidly repeating seismic sources.

\section{Results and interpretation}

\subsection{Repeating seismicity waveforms and recurrence timing}

The stacked waveforms of these repeater families (Fig. 2 and Fig. S1) do not display any clear body wave arrivals and are dominated by long-duration surface waves as evidenced by the particle motion of N-S oriented Rayleigh waves (Fig. 2b), suggesting a superficial source. The arrival time moveout of each of the nine families are very similar and indicate a common origin towards the south of the seismic network. We 
approximate the velocity of the surface waves with the regional shear wave speed (Iglesias et al., 2010) and locate each repeater family using the location method of Frank et al. (2014), which maximizes the aligned and stacked seismic energy over a 3-D grid of possible regional locations. Given the linear nature of the seismic network and that we can only locate each event family with one seismic phase, the resulting locations are are not well constrained. Taking advantage of their similar moveouts, we instead determine a general location for all nine repeater families by stacking their location likelihoods. The maximum of the stacked

50 location likelihood distribution shown in Fig. 1 is close to the surface in a minimally populated region of heavy mining activity in Guerrero.

Looking at the occurence of the repeating seismicity, we frequently observe the events with recurrence intervals, or inter-event times, measured in multiples of a day (Fig. 3 and Fig. S1), where the first event of the day is closely followed in a matter of seconds to hours by a number of multiplets from the same source.

55 These bursts are consistently observed at around 4 PM local time every day of the week except Sunday. Histograms of the repeater seismicity as a function of hour of day and weekday (Fig. 3b and c) show that the large majority of seismicity occurs between 2 and 7 PM (local Central Standard Time) and that there is about $80 \%$ less chance of observing an event on Sunday during the afternoon compared to any other day of the week. We finally compare the observed activity pattern with that of the previously reported repeating 60 low-frequency earthquakes (Frank et al., 2014) in Fig. S2 and find that hour of day and weekday occurrence of the low-frequency earthquakes is clearly different. We therefore suggest that these nine repeating families are a distinct event type that originates from a shallow source region and not from the subduction interface at $40 \mathrm{~km}$ depth.

We acknowledge that there is the possibility that the repeating seismicity we report here is is not triggered 65 seismicity within the crust but actually controlled blasts that originate from the mine. Discriminating between the two possibilities is difficult as both mining blasts and earthquakes can generate the distinct low-frequency stacked repeater family waveforms (see Fig. 2 and Fig. S3) at the distances that we observe ( 100 km to AMAC) (pers. comm. Joan Gomberg, Jul 27 2015). We suggest, however, that the repeaters reported here are more likely to be crustal seismicity because mining blasts are usually programmed on a strict schedule

70 between shifts (typically between 3 and 6 PM) and are not set at night (pers. comm. Gerrit Olivier, Nov 20 2015), making it difficult to explain the rest-of-day seismicity as controlled blasts.

\subsection{Triggering by anthropogenic activity}

Taking into account these different observations, we suggest that the observed repeaters are seismic events modulated by local mining activity. A recent study of the local seismicity near Beijing, China observed a

75 similar apparent link between mining-related activities and triggered seismic events (Wang et al., 2015). To separate the cataloged repeater seismicity into groups based on whether the events are potentially dynamically triggered by human activity, we divide the events for each of the nine families into two populations based on the hour they were detected (see Fig. 3b): (1) afternoon events that were observed between 2 and 7 PM 
local time and are most likely triggered by controlled mining blasts; (2) rest-of-day events that were detected 80 outside of that time period.

We first compare the stacked waveforms of the two different event populations for each family, an example of which is shown in Fig. S4. The stacked waveforms are extremely similar with the same onset times and phases throughout the wave train being reproduced in both populations across the entire network. This waveform similarity implies that the two different population of events originate from the same seismic source. We note that only five of the ten stations were used for the matched-filter search to reduce the computational cost. The high signal-to-noise ratios for both event populations on PLAT, XALI, and TONA that were not used for the detection of the repeater event family in Fig. S4 also ensures that the majority of rest-of-day events are not false detections.

We suggest therefore that the afternoon population represents the events triggered by mining blasts, 90 while the rest-of-day events represent the ambient seismicity not directly induced by blasts. We note as a caveat that the proximity of the repeater families to a large open-pit mine is likely not a coincidence: long term changes to the local stress field caused by mining activity as well as the potential for delayed triggering by controlled blasts are likely contributing factors in facilitating the rest-of-day seismicity (McGarr et al., 2002). To refine the repeating seismicity's location, we stacked the waveforms at MEIG, a broadband seismic

95 station maintained by the Servicio Sismológico Nacional and collocated at the MEZC cGPS station, close to the largest local mine, the Los Filos gold mine (see Fig. 11). Using the event times detected with the MASE network (Caltech, 2007), the stacked waveforms for all nine families at MEIG are observed before XALI, the first arrival MASE station (see Fig. S1). We then rotated the horizontal components at MEIG $40^{\circ}$ clockwise from North to the radial and transverse components with respect to the source-receiver azimuth, using the

100 Los Filos mine as the source location. Such a rotation suppressed the first arrival phase on the transverse component, suggesting that it is a P-wave. We show an example in Fig. S5 with time delays between the picked P, S, and Rayleigh phases that correspond to a source less than $10 \mathrm{~km}$ from MEIG, which, along with the $40^{\circ}$ azimuth, support our interpretation that this superficial repeating seismicity originates close to the Los Filos mine.

105 To evaluate whether the afternoon population is triggered, we picked the maximum amplitude for every event within the frequency band of $1-2 \mathrm{~Hz}$ that the events were detected in. We find that the amplitudes of the afternoon population for each family are systematically two to five times larger than the rest-of-day population (Fig. S6). This is a similar to observations of triggered tectonic tremor (Rubinstein et al., 2007; Peng et al., 2008) that have amplitudes ten times larger than ambient tremor and supports our idea that the afternoon population represents triggered seismicity. Despite the low signal-to-noise ratio (Fig. S6), we still observe a relatively fast seismicity rate of more than 100 rest-of-day events per year per source, which along with a strong sensitivity to dynamic stress perturbations during the afternoon suggests the repeater sources are in a critically stressed state. 


\subsection{Long-term evolution of repeater seismicity}

115 To investigate the long-term rate evolution of the repeater seismicity during the 2006 slow slip event, we perform an analysis used recently to investigate fault conditions along the Guerrero subduction interface (Frank et al., 2014, 2015b). We first calculate the cumulative event count for the entire 2.5 year duration of the dataset and then remove the linear trend that explains the nearly constant activity observed before April 2006, the start of the 2006 slow slip event. This detrended cumulative event count is computed for each of the nine repeater families and is shown alongside the detrended surface displacement measured by two local cGPS are shown in Fig. 3k. Over a period of six months in 2006, we observe a significant increase of repeater activity that starts synchronously with the GPS displacement that is associated with the slow slip event. The repeater seismicity and the GPS then return to pre-slow slip rates at the same time. We note that we are, however, unable to categorically reject the possibility that the increased repeater seismicity

125 is due to an unrelated but coincident increase of the rate of mining activity given that we were not able to obtain the mining blast record.

One possible interpretation of this transient increase of superficial seismicity is that it is the response to a temporary change of the local stress field near the surface resulting from the extension of the continental crust during the slow slip. Because the increased rate of repeater seismicity returns to previous levels after the slow

130 slip event, the transient stress change is correlated with the rate of seismicity and, consequently, the strain rate of the slow slip event, similar to what was observed for crustal seismic velocity changes (Rivet et al., 2011, 2014). This correlation between stress and strain rate implies a crustal rheology that is at least partially viscous. We use the time history of the inverted static strain within the continental crust that was constrained from cGPS observations to estimate the resulting elastic stress perturbation (Radiguet et al.,

135 2011). The maximum transient dilatancy increment less than $10 \mathrm{~km}$ from the surface is about $10^{-7}$. We apply the volumetric stress-strain relationship of $\sigma=K \epsilon$, where $\sigma$ is the stress, $K$ is the bulk modulus, and $\epsilon$ is the dilatancy or volumetric strain. If we multiply the estimated transient dilatancy by a typical crustal bulk modulus of $40 \mathrm{GPa}$, the predicted stress perturbation at the surface during a large slow slip event is on the order of $4 \mathrm{kPa}$. This stress perturbation is on the same order of magnitude as the stresses induced by passing teleseismic waves and tidal loading that have been seen to trigger other low effective stress phenomena, such as tectonic tremor and icequakes (Thomas et al., 2009; Peng et al., 2014; Gomberg et al., 2008; Nakata et al., 2008; Zigone et al., 2012).

\subsection{Modulation by earth and ocean load tides}

If the repeater events are susceptible to transient stresses as small as several $\mathrm{kPa}$, one would expect them

145 to also be sensitive to tidally induced stresses. The strong 24 hour periodicity induced by the daily mining activity, however, makes it difficult to determine through standard tidal analyses (e.g. Thomas et al., 2009) whether the rest-of-day seismicity is correlated with the tides. We therefore develop a new method to analyze the potential tidal modulation of the repeated seismicity. 
We first model the strains due to the ocean load and the solid Earth body tides at the surface at the 150 MEZC cGPS station for every hour during the analyzed 2.5 year dataset using the SPOTL program (Agnew, 2012). Given the shallow source depth, we assume plane strain and model the 2-D horizontal strain tensor every hour. This therefore provides us with the set of strain tensors during the analyzed dataset, $\epsilon_{i j}(t)$, where $t$ is time discretely sampled every hour and $i$ and $j$ are the tensor components and respectively represent east-west and north-south strain. We can then convert each strain tensor to its equivalent stress tensor, 155 assuming linear elasticity and a typical shear modulus of $35 \mathrm{GPa}$. The resulting stress tensor $\sigma_{i j}(t)$ has three independent components: $\sigma_{i i}, \sigma_{j j}$, and $\sigma_{i j}=\sigma_{j i}$. To reduce the number of independent quantities from three to two, we represent the stress tensor at each time $t$ by its: (1) average principal extensional stress, $\sigma^{e}(t)$ and (2) maximum shear stress, $\sigma^{s}(t)$.

To avoid the strong daily periodicity of the afternoon events, we first resample $\sigma^{e}(t)$ and $\sigma^{s}(t)$ to remove the time periods that correspond to the afternoon (2- $7 \mathrm{PM})$, giving us $\sigma^{e}\left(t_{r}\right)$ and $\sigma^{s}\left(t_{r}\right)$ where $t_{r}$ represents all hours during the 2.5 year dataset outside the afternoon hours. These two quantities, $\sigma^{e}\left(t_{r}\right)$ and $\sigma^{s}\left(t_{r}\right)$, therefore represent the modeled distribution of stresses expected for a Poisson occurence of events for the rest-of-day hours. To compare this modeled distribution to the observed distribution of stresses during the rest-of-day events, we resample $t_{r}$ to the set of rest-of-day event times $\tau_{r}$ (rounded to the nearest hour).

165 The observed distribution of principal and maximum shear stresses during the rest-of-day events is therefore represented as $\sigma^{e}\left(\tau_{r}\right)$ and $\sigma^{s}\left(\tau_{r}\right)$.

Now that we can directly compare the observed distribution of the principal and maximum shear stresses to the modeled distributions, we compute the histogram of both stresses, $\sigma^{e}$ and $\sigma^{s}$, for the observed $(O)$ distribution hours $\tau_{r}$ and the modeled $(M)$ distribution hours $t_{r}$ using 50 bins and then apply a 10-bin width

170 smoothing filter (see Fig. 4h). We then calculate the normalized difference between the two stress histograms as $(O-M) / M$. A positive difference at a given stress indicates more events are observed than expected if the event timing was completely uncorrelated with the tidally induced stress.

As shown in Fig. 4, we find that there is a significant difference between the modeled and observed distributions of the average principal extensional stress with more than a $10 \%$ event excess during extension. This

175 observation is corroborated by the distribution of average principal stress rates shown in Fig. 4r, computed as described above and then taking the hourly derivative of the average principal stress. More repeater events occur than expected when stress rates are close to zero and associated with stress maxima and minima. That there are less observed events during periods of rising stress and more events than expected during periods of falling stress suggest that the repeating seismicity occurs after the stress reaches a maximum and therefore not at stress minima. Comparing the modeled and observed maximum shear stress, we do not observe any systematic differences. We therefore suggest that the repeater events are modulated by tidal stresses and are most likely to occur during peak periods of extension. 


\section{Discussion and conclusions}

Following our observations of mining blast triggering and modulation by tides and slow slip, we propose that the repeater sources are in a low effective normal stress environment. This is in contrast to the larger repeating earthquakes observed along the San Andreas fault and in Japan (Nadeau and McEvillv, 1999; Igarashi et al., 2003; Uchida et al., 2003) that do not exhibit any tidal modulation (Thomas et al., 2009). Along with indirect evidence of a volumetric deformation (Rivet et al., 2011, 2014), we suggest that a nonlinear transient extension within the crustal column is correlated with the slip rate of the large 2006 slow slip event and this transient extension further reduces the effective normal stress in the repeater source region and increases the probability that an event will be triggered. The critically stressed environment of these repeaters, as evidenced by the correlation of their activity with stress perturbations of several $\mathrm{kPa}$ due to tides and slow slip, is likely linked to the presence of fluids (Jödicke et al., 2006) similar to other low effective normal stress phenomena such as low-frequency earthquakes, tectonic tremors, and icequakes (Thomas et al., potential factors that could contribute to a low stress environment, such as a weak host rock that is strongly fractured or a less consolidated lithology that could be expected in the shallow crust.

The repeating seismicity that we report here is distinct from the repeating earthquakes that have been observed in other regions (e.g. Vidale et al., 1994; Nadeau et al., 1995; Igarashi et al., 2003), for two reasons:

200 (1) the repeating sources are not located along a plate boundary, and (2) the seismicity rates we observe are an order of magnitude faster ( $>300$ events per year per source). Our results therefore show that low effective stress repeating seismicity such as low-frequency earthquakes can occur within the shallow crust and the tectonic conditions necessary for low stress phenomena are not limited to plate boundaries.

\section{References}

\section{References}

Agnew, D. C., Mar. 2012. SPOTL: Some Programs for Ocean-Tide Loading. Scripps Institution of Oceanography Technical Report.

Audet, P., Bostock, M. G., Christensen, N. I., Peacock, S. M., 2009. Seismic evidence for overpressured subducted oceanic crust and megathrust fault sealing. Nature 457 (7225), 76-78.

210 Caltech, Apr. 2007. Meso-America Subduction Experiment (MASE) dataset.

Cavalie, O., Pathier, E., Radiguet, M., Vergnolle, M., Cotte, N., Walpersdorf, A., Kostoglodov, V., Cotton, F., Apr. 2013. Slow slip event in the Mexican subduction zone: Evidence of shallower slip in the Guerrero seismic gap for the 2006 event revealed by the joint inversion of InSAR and GPS data. Earth Planet. Sci. Lett. $367,52-60$. 
215 Frank, W. B., Radiguet, M., Rousset, B., Shapiro, N. M., Husker, A. L., Kostoglodov, V., Cotte, N., Campillo, M., 2015a. Uncovering the geodetic signature of silent slip through repeating earthquakes. Geophys. Res. Lett. 42 .

Frank, W. B., Shapiro, N. M., Apr. 2014. Automatic detection of low-frequency earthquakes (LFEs) based on a beamformed network response. Geophys. J. Int. 197 (2), 1215-1223.

220 Frank, W. B., Shapiro, N. M., Husker, A. L., Kostoglodov, V., Bhat, H. S., Campillo, M., Jan. 2015b. Alongfault pore-pressure evolution during a slow-slip event in Guerrero, Mexico. Earth Planet. Sci. Lett. 413, 135-143.

Frank, W. B., Shapiro, N. M., Husker, A. L., Kostoglodov, V., Romanenko, A., Campillo, M., Nov. 2014. Using systematically characterized low-frequency earthquakes as a fault probe in Guerrero, Mexico. J. 225 Geophys. Res. 119, 7686-7700.

Gibbons, S. J., Ringdal, F., 2006. The detection of low magnitude seismic events using array-based waveform correlation. Geophys. J. Int. 165 (1), 149-166.

Gomberg, J. S., Rubinstein, J. L., Peng, Z., Creager, K. C., Vidale, J. E., Bodin, P., 2008. Widespread triggering of nonvolcanic tremor in California. Science 319, 173-173.

230 Igarashi, T., Matsuzawa, T., Hasegawa, A., 2003. Repeating earthquakes and interplate aseismic slip in the northeastern japan subduction zone. J. Geophys. Res. 108, B52249.

Iglesias, A., Clayton, R. W., Pérez-Campos, X., Singh, S. K., Pacheco, J. F., Garcia, D., Valdés-González, C., Jun. 2010. S-wave velocity structure below central Mexico using high-resolution surface wave tomography. J. Geophys. Res. 115, B06307-10.

235 Jödicke, H., Jording, A., Ferrari, L., Arzate, J., Mezger, K., Rüpke, L., 2006. Fluid release from the subducted Cocos plate and partial melting of the crust deduced from magnetotelluric studies in southern Mexico: Implications for the generation of volcanism and subduction dynamics. J. Geophys. Res. 111, B08102.

Kim, Y., Clayton, R. W., Asimow, P. D., Jackson, J. M., Dec. 2013. Generation of talc in the mantle wedge and its role in subduction dynamics in central Mexico. Earth Planet. Sci. Lett. 384, 81-87.

240 Kostoglodov, V., Husker, A. L., Shapiro, N. M., Payero, J. S., Campillo, M., Cotte, N., Clayton, R. W., 2010. The 2006 slow slip event and nonvolcanic tremor in the Mexican subduction zone. Geophys. Res. Lett. 37, L24301.

McGarr, A., Simpson, D., Seeber, L., 2002. Case histories of induced and triggered seismicity. In: William H.K. Lee, Hiroo Kanamori, P. C. J., Kisslinger, C. (Eds.), International Handbook of Earthquake and Engineering Seismology. Vol. 81, Part A of International Geophysics. Academic Press, pp. 647 - 661. 
Nadeau, R. M., Foxall, W., McEvilly, T. V., 1995. Clustering and periodic recurrence of microearthquakes on the san andreas fault at parkfield, california. Science 267 (5197), 503-507.

Nadeau, R. M., McEvilly, T. V., 1999. Fault slip rates at depth from recurrence intervals of repeating microearthquakes. Science 285 (5428), 718-721.

250 Nakata, R., Suda, N., Tsuruoka, H., 2008. Non-volcanic tremor resulting from the combined effect of earth tides and slow slip events. Nature Geoscience 1 (10), 676-678.

Obara, K., 2002. Nonvolcanic deep tremor associated with subduction in southwest Japan. Science 296, $1679-1681$.

Peng, Z., Vidale, J. E., Creager, K. C., Rubinstein, J. L., Gomberg, J. S., Bodin, P., 2008. Strong tremor near Parkfield, CA, excited by the 2002 Denali Fault earthquake. Geophys. Res. Lett. 35 (23).

Peng, Z., Walter, J. I., Aster, R. C., Nyblade, A., Wiens, D. A., Anandakrishnan, S., Sep. 2014. Antarctic icequakes triggered by the 2010 Maule earthquake in Chile. Nature Geosci. 7 (9), 677-681.

Radiguet, M., Cotton, F., Vergnolle, M., Campillo, M., Valette, B., Kostoglodov, V., Cotte, N., 2011. Spatial and temporal evolution of a long term slow slip event: the 2006 Guerrero Slow Slip Event. Geophys. J. Int. $184(2), 816-828$.

Rivet, D., Campillo, M., Radiguet, M., Zigone, D., Cruz-Atienza, V. M., Shapiro, N. M., Kostoglodov, V., Cotte, N., Cougoulat, G., Walpersdorf, A., Daub, E. G., Jan. 2014. Seismic velocity changes, strain rate and non-volcanic tremors during the 2009-2010 slow slip event in Guerrero, Mexico. Geophys. J. Int. 196, $447-460$.

265 Rivet, D., Campillo, M., Shapiro, N. M., Cruz-Atienza, V. M., Radiguet, M., Cotte, N., Kostoglodov, V., 2011. Seismic evidence of nonlinear crustal deformation during a large slow slip event in Mexico. Geophys. Res. Lett. 38, L08308.

Rubinstein, J. L., Vidale, J. E., Gomberg, J. S., Bodin, P., Creager, K. C., Malone, S. D., 2007. Non-volcanic tremor driven by large transient shear stresses. Nature 448, 579-582.

270 Shelly, D. R., Beroza, G. C., Ide, S., Nakamula, S., 2006. Low-frequency earthquakes in Shikoku, Japan, and their relationship to episodic tremor and slip. Nature 442 (7099), 188-191.

Song, T.-R. A., Helmberger, D. V., Brudzinski, M. R., Clayton, R. W., Davis, P., Pérez-Campos, X., Singh, S. K., 2009. Subducting slab ultra-slow velocity layer coincident with silent earthquakes in southern mexico. Science 324 (5926), 502-506.

275 Thomas, A. M., Nadeau, R. M., Bürgmann, R., Dec. 2009. Tremor-tide correlations and near-lithostatic pore pressure on the deep San Andreas fault. Nature 462, 1048-1051. 
Uchida, N., Matsuzawa, T., Hasegawa, A., Igarashi, T., 2003. Interplate quasi-static slip off sanriku, ne japan, estimated from repeating earthquakes. Geophysical Research Letters 30 (15).

Vidale, J., ElIsworth, W., Cole, A., Marone, C., 1994. Variations in rupture process with recurrence interval in a repeated small earthquake. Nature 368, 624-626.

Wang, W., Meng, X., Peng, Z., Chen, Q.-F., Liu, N., 2015. Increasing background seismicity and dynamic triggering behaviors with nearby mining activities around fangshan pluton in beijing, china. J. Geophys. Res. 120 (8), 5624-5638.

Zigone, D., Rivet, D., Radiguet, M., Campillo, M., Voisin, C., Cotte, N., Walpersdorf, A., Shapiro, N. M., 285 Cougoulat, G., Roux, P., 2012. Triggering of tremors and slow slip event in Guerrero, Mexico, by the 2010 Mw 8.8 Maule, Chile, earthquake. J. Geophys. Res. 117, B09304.

\section{Acknowledgments}

We thank Mathilde Radiguet, Diane Rivet, and Nathalie Cotte for providing us with the 2006 slowslip event dilatancy and GPS data as well as Caltech for making the analyzed Meso-America Subduction

290 Experiment dataset available. We also thank Gregor Hillers, Gerrit Olivier, Zhigang Peng, Amanda Thomas, Andrey Khokhlov, Duncan Agnew, and Luis Rivera for discussions that improved this manuscript. SSN data was obtained by the Servicio Sismológico Nacional (México) and acquisition and distribution was thanks to its personnel. This work was supported by the Agence Nationale de la Recherche (France) under the contract RA0000CO69 (G-GAP) and the DataScale project, by the European Research Council under the contract

295 FP7 ERC Advanced grant 227507 (WHISPER), by PAPIIT IN110514 and CONACYT 178058 (Mexico), by the Russian Science Foundation (grant 14-47-00002), and by the National Science Foundation (NSF) grant EAR-PF 1452375 . 
Figure 1: Rapid superficial repeaters in Guerrero, Mexico. The blue, inverted triangles represent the analyzed seismic network (stations from north to south: AMAC, CASA, BUCU, CIEN, TOMA, ZACA, SATA, TONA, XALI, and PLAT) and the green triangles represent two local GPS stations. The yellow star represents the location of the Los Filos gold mine, shown in the inset (C) Google Earth). The distribution of the summed beamformed network response (Frank and Shapiro, 2014) of the nine event families between $90 \%$ and $100 \%$ of the maximum likelihood is shown in both panels. The geometry of the top of the subducting Cocos slab is shown by the contours in a and the solid black line in b (Kim et al., 2013). (a.) The yellow patch shows the area of the subduction interface that slipped more than 10 and $15 \mathrm{~cm}$ (dashed contours) during the 2006 slow slip event (Cavalie et al., 2013). (b.) The portion of the subduction interface that slipped more than $15 \mathrm{~cm}$ during the 2006 slow slip event is indicated by the yellow patch (Cavalie et al., 2013). The dotted inverted triangle indicates a patch of high conductivity, evidenced by a magneto-telluric study (Jödicke et al., 2006).

Figure 2: Rapid superficial seismic repeater waveforms and particle motions. The stacked waveforms of the repeater families (a) are dominated by long duration surface waves (filtered here in the analyzed 1-2 $\mathrm{Hz}$ frequency band), whose partial motion (b) suggest a N-S oriented Rayleigh wave. Both afternoon (in red) and rest-of-day (in dark grey) event populations produce the same stacked waveforms, confirming that the observed repeater events originate from the same source regardless of the hour of day.

Figure 3: Modulation of low effective stress repeating seismicity. a. The recurrence intervals for each of the nine families, containing a total of 8121 multiplets, plotted on top of one another. The two horizontal red lines, plotted at recurrence intervals of one and two days, highlight the observed characteristic recurrence activity of the repeaters. The repeater events are divided into two populations based on the hour of day that they occur (b): the majority which occurs during the afternoon between 2 and 7 PM (red); and the rest-of-day events (dark gray). The weekday distribution (c) of the afternoon population shows an $\sim 80 \%$ less chance to observe events on Sunday, suggesting an anthropogenic influence, compared with the rest-of-day events that are equally distributed throughout the week. d. This is confirmed visually by arbitrarily plotting dotted lines at 4 PM every day of the week (except Sundays, shown as red patches). e. The mean detrended cumulative count of the nine repeater families (black) represents the long-term activity of the repeater families; the individual activity trends of the nine families are plotted in grey. There is a significant increase of repeater activity that is synchronous with the large 2006 slow slip event, as evidenced by the surface displacement at the closest cGPS station MEZC (plotted in solid purple for south-north and dashed purple for west-east).

Figure 4: Evaluating the modulation of the repeater seismicity by tidally induced principal stresses. Due to the strong daily periodicity of the afternoon events, we only consider the rest-of-day events and time period. The modeled (dashed line) and observed (solid red) normalized histograms, or probability distributions, of the average principal stress in (a) are significantly different at positive stress, representing extension. This is further emphasized in (b), where an observed event excess at high positive stresses implies a tidal modulation of the repeater events during extension. The difference between the modeled (dashed line) and observed (solid red) normalized probability distributions of the average principal stress rate in (c) show that significantly more repeater events occur at peak stress (when the stress rate $=0$ ). 


\section{Figure 1}

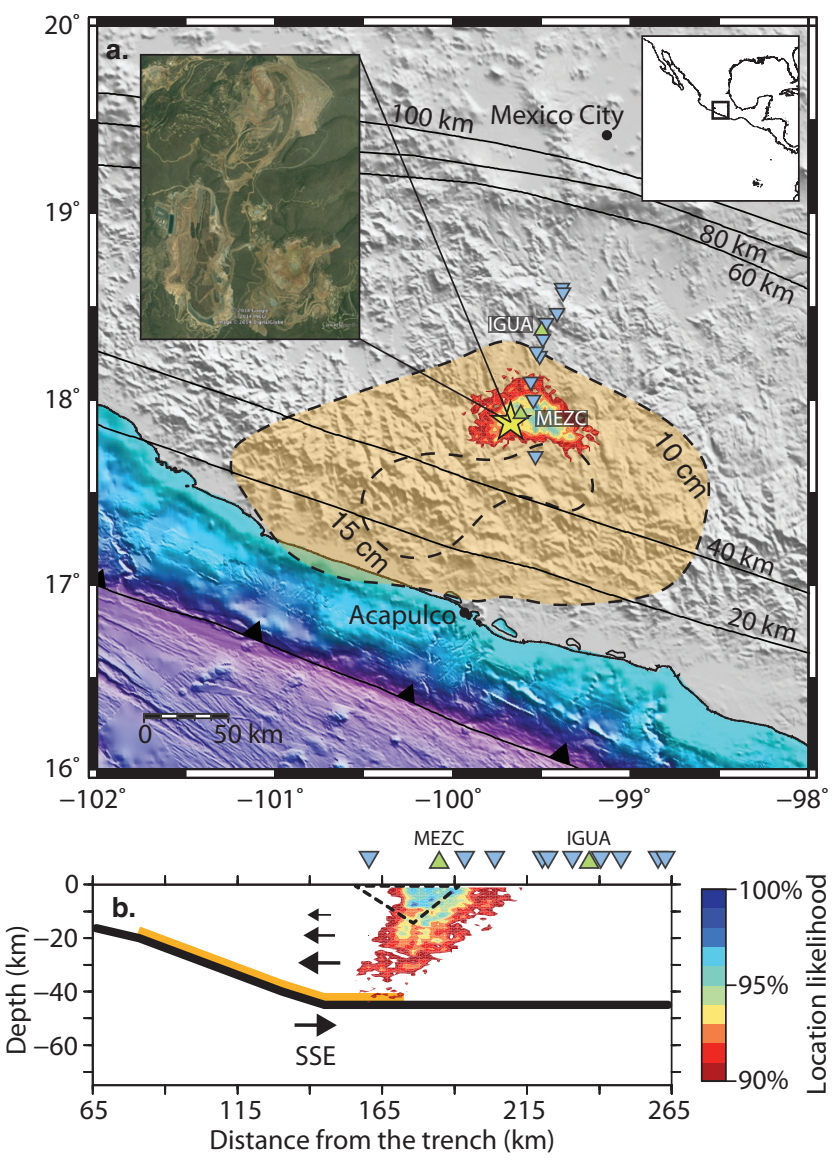


Figure 2
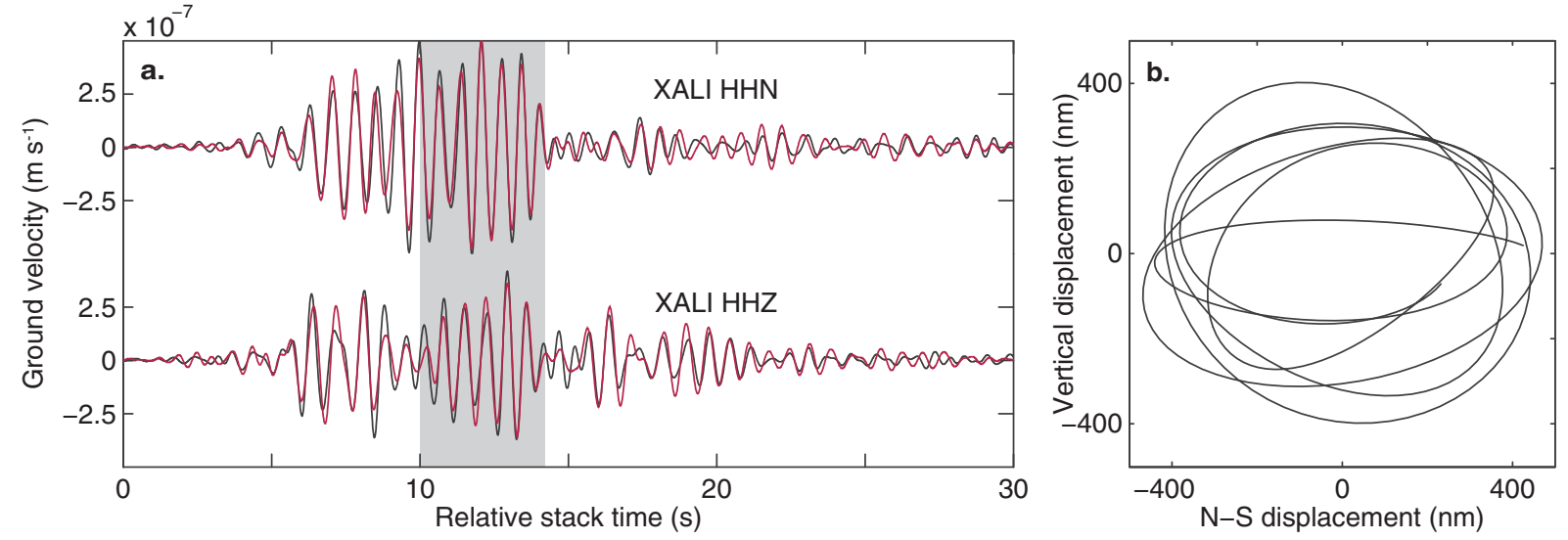
Figure 3
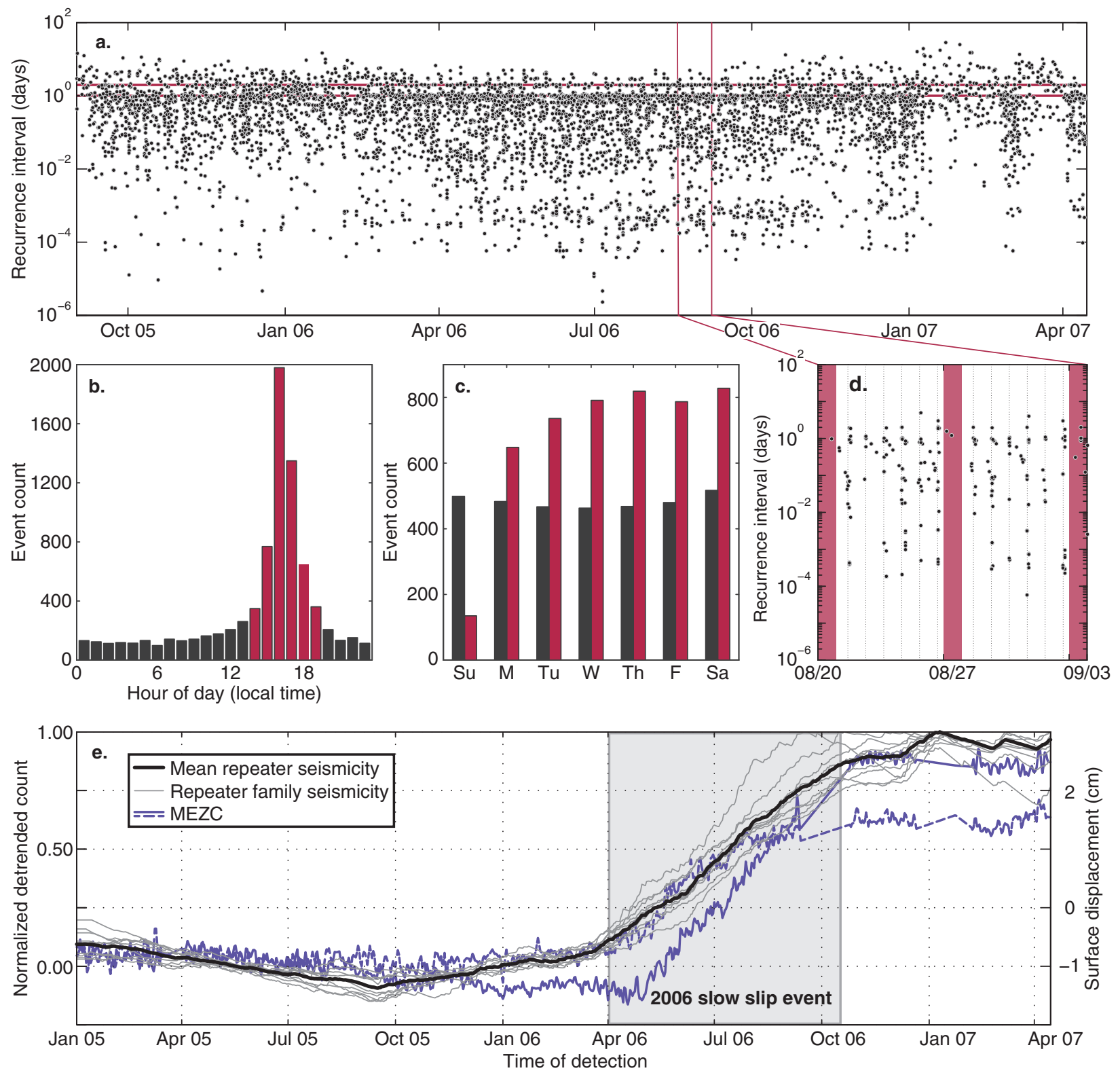
Figure 4
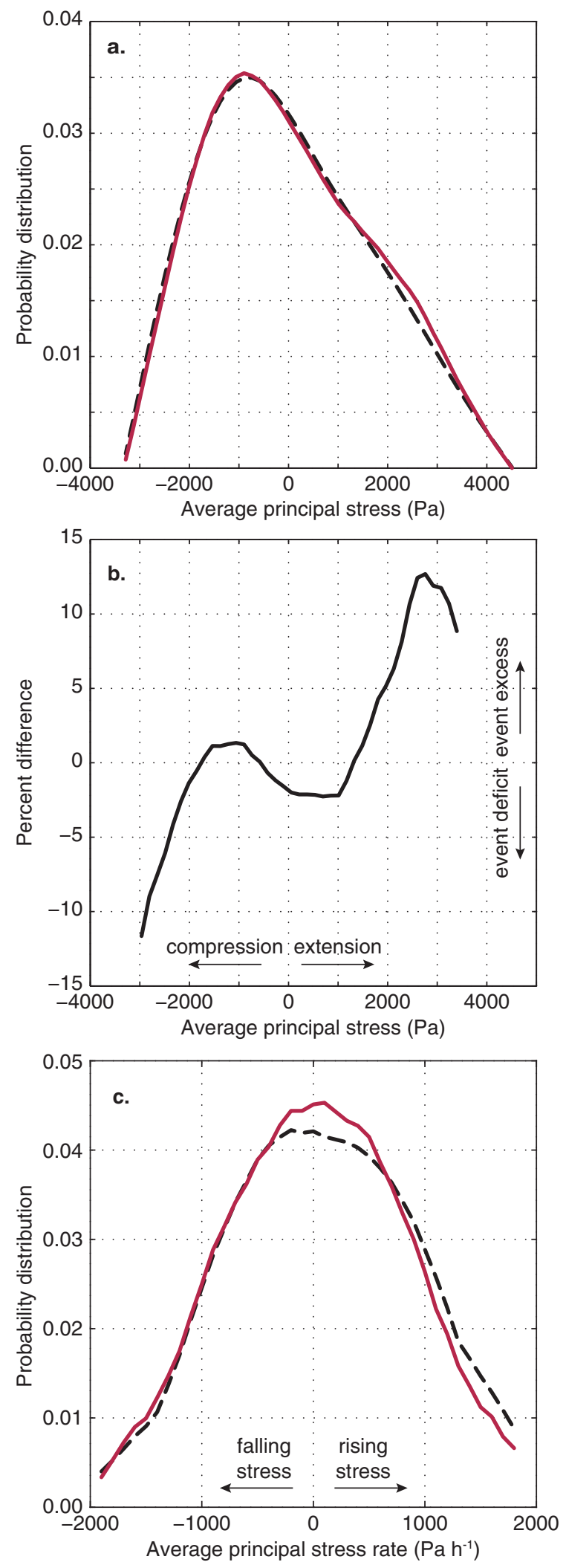